\title{
All-enzymatic HPLC method for determination of individual and total contents of vitamin $B_{6}$ in foods
}

\author{
Huong Thi Viet Do, Youhei Ide, Andrew Njagi Mugo and \\ Toshiharu Yagi*
}

Faculty of Agriculture and Agricultural Science Program, Graduate School of Integrated Arts and Sciences, Kochi University, Nankoku, Kochi, Japan

Abstract

Background: There is a need for a reliable and accurate method for quantification of each of the seven individual vitamin $\mathrm{B}_{6}$ compounds including pyridoxine- $\beta$-glucoside in foods.

Objective: To determine pyridoxal (PL), pyridoxamine (PM), pyridoxine (PN), pyridoxal 5'-phosphate (PLP), pyridoxamine 5'-phosphate (PMP), pyridoxine 5'-phosphate (PNP), and pyridoxine- $\beta$-glucoside (PNG) in foods.

Design: By specific enzymatic treatment, each of the seven vitamin $\mathrm{B}_{6}$ compounds was all converted into 4-pyridoxolactone, which is a highly fluorescent compound. In total, seven separate, enzymatic steps were performed for each sample. Separation and quantification were performed with reversed-phase high performance liquid chromatography (HPLC) coupled with fluorescence detection. For each sample type the result was corrected for the recovery based on spiked samples. The method was applied for analyses of chicken liver, chicken white meat, egg yolk, egg white, dried anchovy, carrots, and garlic.

Results: The recovery varied from 14 to $114 \%$ in chicken liver, chicken white meat, egg yolk, egg white, dried anchovy, carrot, and garlic. Each food showed a characteristic distribution of the seven vitamin $\mathrm{B}_{6}$ compounds. The PNG was only found in low amounts; that is, 17-29 nmol vitamin $\mathrm{B}_{6} / \mathrm{g}$ in the plant-derived foods, carrot and garlic. Only egg white showed a lower content, $3 \mathrm{nmol} / \mathrm{g}$. Overall the content in chicken liver, chicken white meat, and egg yolk had a total content of vitamin $\mathrm{B}_{6}$ between 42 and $51 \mathrm{nmol} / \mathrm{g}$. Both PM and PMP were high in the chicken liver. In contrast, PL and PLP were high in the chicken white meat. The main vitamin $\mathrm{B}_{6}$ in the egg yolk was PLP. The dried anchovy contained high amounts of PLP and PMP and a total content of $144 \mathrm{nmol} / \mathrm{g}$.

Conclusions: The enzymatic-based HPLC method was applied for the determination of seven vitamin $\mathrm{B}_{6}$ compounds in foods. Their distribution in the foods varied significantly.

Keywords: pyridoxal; pyridoxamine; pyridoxine; phosphates; pyridoxine- $\beta$-glucoside

$\mathrm{N}$ atural foods contain seven vitamin $\mathrm{B}_{6}$ compounds: pyridoxine $(\mathrm{PN})$, pyridoxal $(\mathrm{PL})$, pyridoxamine (PM), the phosphoester forms (PNP, PLP, PMP), and pyridoxine- $\beta$-glucoside (PNG). Their structures are shown in Fig. 1. The total contents of vitamin $\mathrm{B}_{6}$ in foods have been determined by the microbioassay with a yeast Saccharomyces cerevisiae (1). The contents, thus, are converted to and expressed as $\mathrm{PN}$. The procedure has been done according to an AOAC protocol (AOAC Official Method 985.32). However, the method suffers disadvantages of inclusion of
PNG in the content, and an insufficient hydrolysis of PMP and PNP in some foods even though the foods are subjected to a drastic hydrolysis under a high pressure (2). The published method shows separate quantification of PN, PL, PM, and PNG (3). The nutritional availability of PNG in the human body is controversial (4).

Recent studies have shown that each of the vitamin $\mathrm{B}_{6}$ compounds has specific functions. The PM prevents and cures the diabetic complications (5). Both PLP and $\mathrm{PMP}$, coenzyme forms of vitamin $\mathrm{B}_{6}$, showed a stronger 


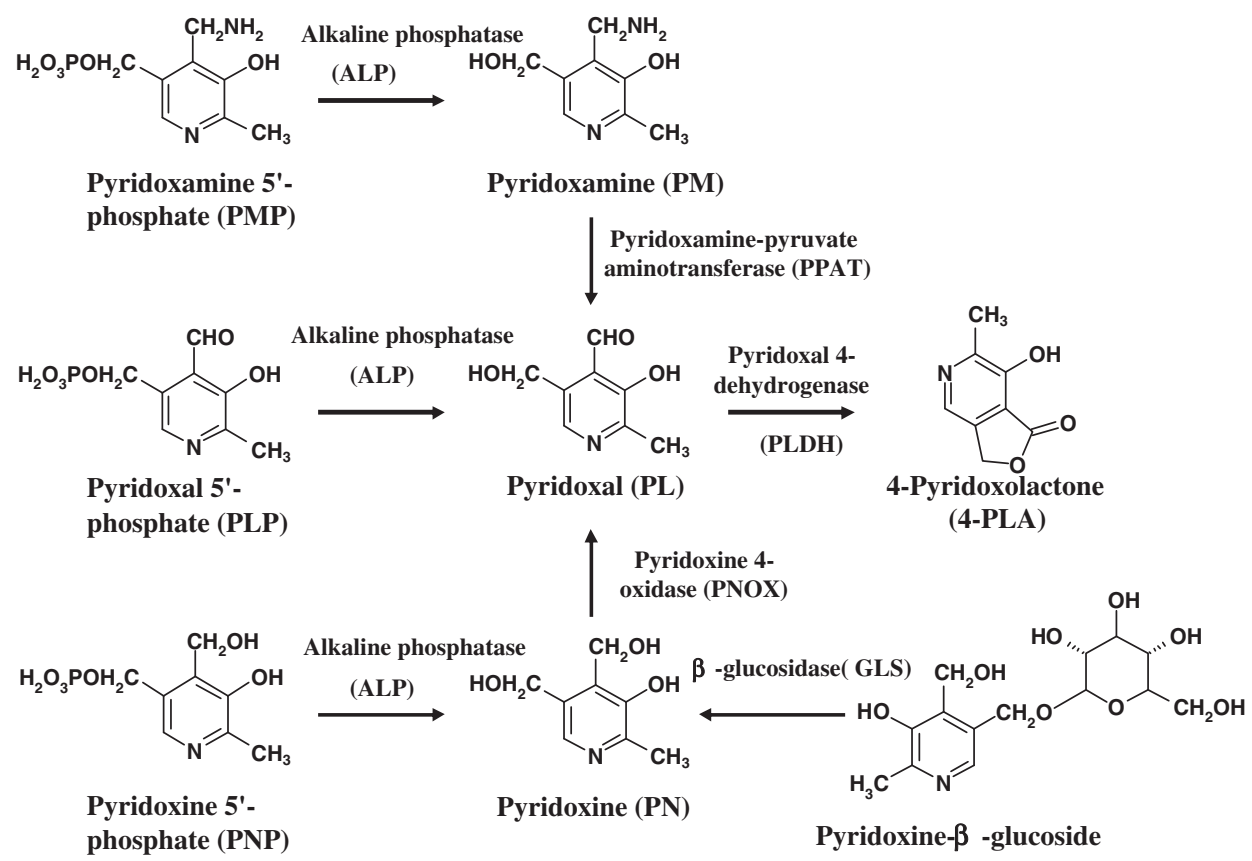

Fig. 1. Strategy for the all-enzymatic HPLC (AEH) method to determine seven vitamin $\mathrm{B}_{6}$ compounds. All of the compounds were specifically and totally converted into 4-pyridoxolactone, a high fluorescent derivative of vitamin $\mathrm{B}_{6}$, which was quantified by a reversed-phase HPLC. Pyridoxal 4-dehydrogenase, pyridoxamine-pyruvate aminotransferase, pyridoxine 4-oxidase, alkaline phosphatase, and $\beta$-glucosidase were used for the conversion.

protection of yeast cells from oxidative death than vitamin C, a well-known antioxidative vitamin (6). Therefore, the individual vitamin $\mathrm{B}_{6}$ content in foods should be determined to estimate their functionality.

Determination of individual vitamin $\mathrm{B}_{6}$ compounds by high performance liquid chromatography (HPLC) methods $(3,7,8)$ are applicable for the samples containing high amounts of vitamin $\mathrm{B}_{6}$ but not for foods containing very low amounts of vitamin $B_{6}$ in combination with high amounts of other fluorescent compounds, which interfere with their identification and determination.

Recently, we have developed a method for determination of individual vitamin $\mathrm{B}_{6}$ compounds based on specific enzymatic conversion of the vitamin $\mathrm{B}_{6}$ compounds into the high fluorescent compound 4-pyridoxolactone (4-PLA) (9). However, the method used the $\mathrm{HCl}$-hydrolysis to convert the phosphoester forms into corresponding free forms. Thus, PNG and PNP were not determined separately, and the recovery of the standards added were very low due to loss by nonspecific reactions with components in the foods such as minerals (9).

The aim of this study was to develop a novel method, which uses enzymatic reactions in all the steps instead of the $\mathrm{HCl}$-hydrolysis and is applicable for determination of the seven individual vitamin $\mathrm{B}_{6}$ compounds in foods.

\section{Materials and methods}

\section{Materials}

Recombinant PL 4-dehydrogenase (PLDH), PM-pyruvate aminotransferase (PPAT), and PN 4-oxidase (PNOX) were prepared as described previously (10-12). Recombinant $E$. coli alkaline phosphatase (ALP) was prepared according to a standard protocol (13). The PNP was prepared from PLP through reduction with sodium borohydride (14). Almond $\beta$-glucosidase (GLS), PM, and PL $(\geq 99.5 \%)$ were purchased from Sigma Chemical Co. (St. Louis, MO), PN and PLP from Nacalai Tesque, Inc. (Kyoto, Japan). The PMP was a gift from Daiichi Fine Chemicals Co. (Takaoka, Japan) and PNG was prepared enzymatically from D-glucose and $\mathrm{PN}$ based on a transglucosidase activity of a bacterial $\beta$-glucosidase (15). Food samples were bought at local markets and chosen at random in order to test and validate the method.

\section{Principle, reaction conditions, and calculation}

The basic principle is to convert all vitamin $\mathrm{B}_{6}$ compounds specifically into a highly fluorescent vitamin $\mathrm{B}_{6}$-derivative 4-PLA (see Fig. 1). Thus, seven reaction mixtures were used to determine seven vitamin $\mathrm{B}_{6}$ compounds. The reaction mixtures are shown in Fig. 2. Fig. 3 illustrate the analytical procedure of the seven reactions carried out. The filtration was done with a Dismic 13 syringe filter (pore size of $0.2 \mu \mathrm{m}$, Advantech, Tokyo, Japan). To make 


Reaction 1 (R1)
$40 \mu \mathrm{L} 250 \mathrm{mM}$ Tris- $\mathrm{HCl}(\mathrm{pH} 9.0)$
$1 \mu \mathrm{L}$ PLDH $(1 \mathrm{U} / \mathrm{mL})$
$2 \mu \mathrm{L} 100 \mathrm{mM} \mathrm{NAD}^{+}$
$5-50 \mu \mathrm{L}$ extract of foods
$332-287 \mu \mathrm{L}$ water

Reaction 4 (R4)

$40 \mu \mathrm{L} 250 \mathrm{mM}$ Tris- $\mathrm{HCl}(\mathrm{pH} 9.0)$

$40 \mu \mathrm{L} 5 \mathrm{mM} \mathrm{MgCl}$

$6 \mu \mathrm{L} \operatorname{ALP}(1.7 \mathrm{U} / \mathrm{mL})$

5-50 $\mu \mathrm{L}$ extract of foods

286- $241 \mu \mathrm{L}$ water
Reaction 2 (R2)

$40 \mu \mathrm{L} 250$ mM Tris- $\mathrm{HCl}$ (pH 9.0)

$1 \mu \mathrm{L}$ PLDH $(1 \mathrm{U} / \mathrm{mL})$

$2 \mu \mathrm{L} 100 \mathrm{mM} \mathrm{NAD}^{+}$

$1 \mu \mathrm{L}$ PPAT $(1 \mathrm{U} / \mathrm{mL})$

$8 \mu \mathrm{L} 100 \mathrm{mM}$ sodium pyruvate

5-50 $\mu \mathrm{L}$ extract of foods

323-278 $\mu \mathrm{L}$ water

Reaction 5 (R5)

$40 \mu \mathrm{L} 250 \mathrm{mM}$ Tris- $\mathrm{HCl}$ (pH 9.0)

$40 \mu \mathrm{L} 5 \mathrm{mM} \mathrm{MgCl}$

$6 \mu \mathrm{L} \operatorname{ALP}(1.7 \mathrm{U} / \mathrm{mL})$

5-50 $\mu \mathrm{L}$ extract of foods

277-232 $\mu \mathrm{L}$ water
Reaction 3 (R3)

$40 \mu \mathrm{L} 250 \mathrm{mM}$ Tris- $\mathrm{HCl}$ (pH 9.0)

$1 \mu \mathrm{L}$ PLDH $(1 \mathrm{U} / \mathrm{mL})$

$2 \mu \mathrm{L} 100 \mathrm{mM} \mathrm{NAD}{ }^{+}$

$1 \mu \mathrm{LL}$ PNOX $(1 \mathrm{U} / \mathrm{mL})$

$1 \mu \mathrm{L} 1 \mathrm{mM}$ FAD

5-50 $\mu \mathrm{L}$ extract of foods

$330-285 \mu \mathrm{L}$ water

Reaction 6 (R6)

$40 \mu \mathrm{L} 250$ mM Tris-HCl (pH 9.0)

$40 \mu \mathrm{L} 5 \mathrm{mM} \mathrm{MgCl} 2$

$6 \mu \mathrm{L} \operatorname{ALP}(1.7 \mathrm{U} / \mathrm{mL})$

5-50 $\mu \mathrm{L}$ extract of foods

284-239 $\mu \mathrm{L}$ water

\section{Reaction 7 (R7)}

$40 \mu \mathrm{L} 500 \mathrm{mM}$ sodium acetate (pH 5.0)

$20 \mu \mathrm{L} 1 \mathrm{M} \mathrm{NaH}_{2} \mathrm{PO}_{4}$

$2 \mu \mathrm{L} \beta$-glucosidase $(25 \mathrm{U} / \mathrm{mL})$

5-50 $\mu \mathrm{L}$ extract of foods

133-88 $\mu \mathrm{L}$ water

Fig. 2. The reaction mixtures used for determination of seven vitamin $\mathrm{B}_{6}$ compounds.

a control (i.e. no-reaction test sample), $\mathrm{HCl}$ was added to the reaction mixture before addition of the food sample. For the determination of PLP, the food sample was at first hydrolyzed with ALP in the reaction 4 (Fig. 2), and then the PL produced was determined as shown under the reaction for PLP (Fig. 3). Both PMP and PNP were determined in the same way just like PLP but using the additional enzymes and the substrate or the cofactor as shown under the reactions for PMP and PNP, respectively (Fig. 3). For the determination of PNG, the food sample was at first hydrolyzed with $\beta$-glucosidase in the reaction mixture containing $\mathrm{NaH}_{2} \mathrm{PO}_{4}$, which inhibited phospha- tase activity in the almond $\beta$-glucosidase preparation, and then PN was determined as shown under the reaction for PNG (Fig. 3).

See Table 1 for quantification of the seven compounds from the HPLC elution profiles of the seven reactions described above. Because the recovery was significantly lower than $100 \%$, the correction was made. All sample analyses were repeated three to four times.

\section{HPLC system and enzyme assay}

The 4-PLA was measured by a reversed-phase isocratic HPLC method using a Cosmosil 5C18MS-II column
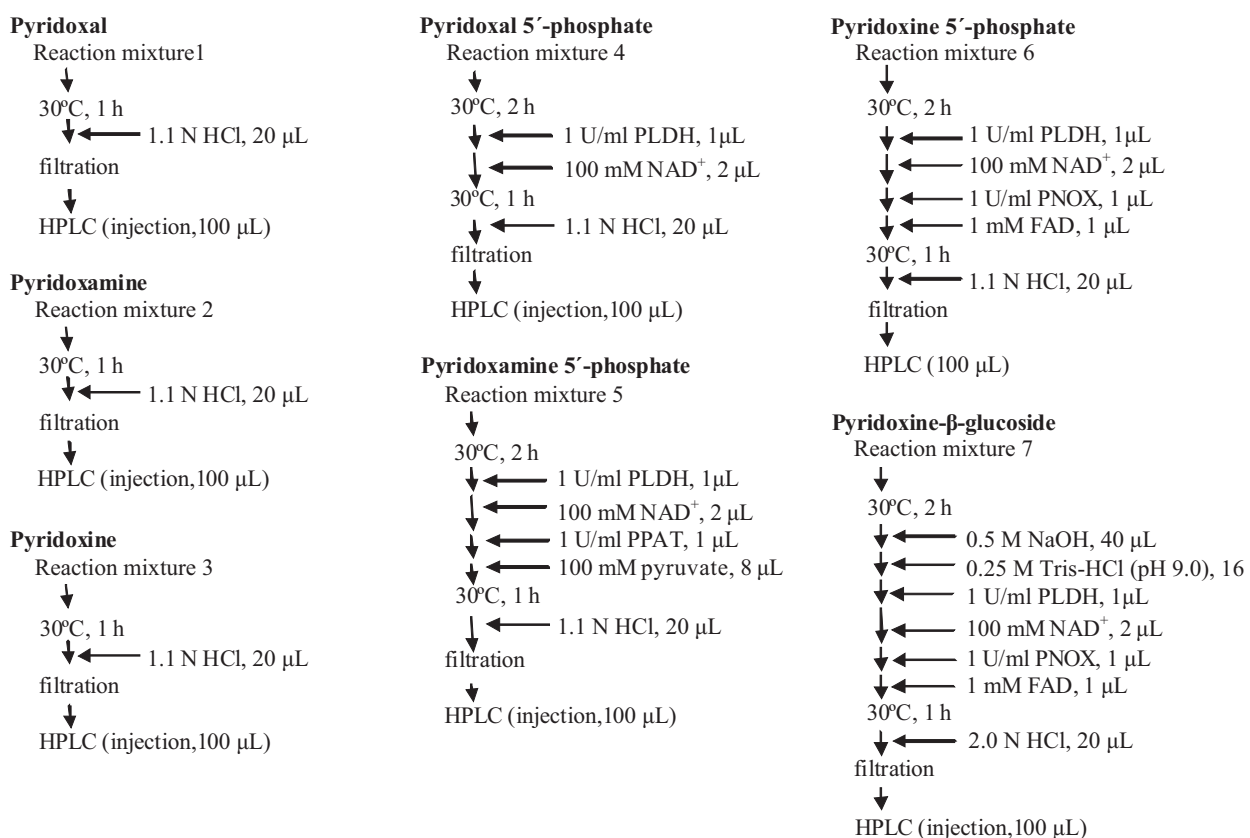

Fig. 3. Illustrations of analytical procedures of seven reactions. Horizontal arrows mean the addition of the solutions to the reaction mixtures. 
Table 1. Calculation of $\mathrm{B}_{6}$-vitamers

\begin{tabular}{ll}
\hline$B_{6}$-vitamer & \multicolumn{1}{c}{ Calculation* } \\
\hline PL & RI \\
PM & R2-RI \\
PN & R3-RI \\
PLP & R4-RI \\
PMP & R5-R4-R2 +RI \\
PNP & R6-R4-R3 +RI \\
PNG & R7-R3 \\
\hline
\end{tabular}

*Area of peak for 4-PLA.

$(250 \times 4.6 \mathrm{~mm}$; Nacalai Tesque, Kyoto, Japan $)$, and a mobile phase consisting of $20 \mathrm{mM}$ potassium phosphate buffer $(\mathrm{pH} 7.0)$ and $10 \%(\mathrm{v} / \mathrm{v})$ methanol. The flow rate and sample volume were $0.5 \mathrm{ml} / \mathrm{min}$ and $100 \mu \mathrm{l}$, respectively. The separation was made with a Jasco HPLC system (JASCO, Tokyo, Japan) equipped with an AS-2055 autosampler, a PU-2080 pump, and an FP-920 fluorescence detector. The fluorescence intensity of the eluted 4-pyridoxolactone was monitored at $430 \mathrm{~nm}$ after excitation at $360 \mathrm{~nm}$.

The PLDH (10), PNOX (12), PPAT (11), ALP (16), and $\beta$-glucosidase (17) were assayed as described previously. One unit of enzyme was defined as the amount that catalyzed the formation of $1 \mu \mathrm{mol}$ of product per min. The PLDH, PNOX, ALP, and $\beta$-glucosidase catalyze irreversible reactions; PPAT catalyzes a reversible reaction. However, when coupled with PLDH the reversible reaction is forced to produce $100 \%$ conversion. For example, the enzymatic reactions shown in Fig. 1 are $100 \%$ conversion of the substrates. The activities of the enzymes were assayed every time just before usage for enzymatic conversion of vitamin $\mathrm{B}_{6}$ compounds into 4-PLA.

\section{Food sample preparation}

Chicken white meat and liver, egg yolk and white, dried anchovy, carrot, and garlic were analyzed. The edible wet part of the foods was used, with the exception of the dried anchovy, which was ground with a Mini Blender (Osaka chemical co., Osaka, Japan). Foods (0.1-1.0 g, dry or wet) were homogenized in $5 \mathrm{ml}$ of $0.1 \mathrm{M} \mathrm{HCl}$ with a Polytron homogenizer, and then the homogenate was incubated at $100^{\circ} \mathrm{C}$ for $30 \mathrm{~min}$ to liberate protein-bound PLP. The suspension was cooled on ice, then $0.1 \mathrm{ml}$ of $50 \%(\mathrm{w} / \mathrm{v})$ trichloroacetic acid (TCA) was added, and followed by incubation at $100^{\circ} \mathrm{C}$ for $5 \mathrm{~min}$. After cooling on ice, $\mathrm{pH}$ of the mixture was adjusted to 7.5 by the addition of $0.5 \mathrm{ml}$ of $0.5 \mathrm{M}$ Tris- $\mathrm{HCl}(\mathrm{pH} 7.5)$ and $0.57 \mathrm{ml}$ of $1.0 \mathrm{M}$ $\mathrm{NaOH}$. The mixture was centrifuged at $8,000 \times \mathrm{g}$ for $5 \mathrm{~min}$ at $4^{\circ} \mathrm{C}$, and then the supernatant $(5-50 \mu \mathrm{l})$ was used for the enzymatic reactions. Samples that were added the seven vitamin $\mathrm{B}_{6}$ compounds were similarly treated to assess recovery. Spiking level was 2 pmol (the amount in $100 \mu \mathrm{l}$ applied to the HPLC column). Recovery test was made two or three times.

\section{Results and discussion}

Determination of vitamin $B_{6}$ compounds in food samples The chromatograms for the analysis of PL, PM, and PN in the chicken liver sample are shown in Fig. 4: They showed similar but definitely different patterns of the fluorescent peaks of 4-PLA. The 4-PLA was eluted at about $11 \mathrm{~min}$ as shown with an arrow, together with unknown fluorescent compounds in the sample. The control reaction showed a tiny peak of 4-PLA (PL, No-R in Fig. 4A), its area increased when the liver sample was subjected to the enzymatic conversion with the reaction 1 in Fig. 2 for converting PL into 4-PLA (PL, $\mathrm{R})$ in the sample. Thus, the subtraction of fluorescence intensity of 4-PLA (PL, No-R) from that of 4-PLA (PL, $\mathrm{R})$ gave the amount of 4-PLA corresponding to the amount of PL in the sample. The chicken liver sample spiked with PL showed a higher peak $(\mathrm{PL}+\mathrm{Sd}, \mathrm{R})$ because the corresponding amount of 4-PLA was additionally produced by the enzymatic conversion. In contrast, the chicken liver sample spiked with PL without the enzymatic conversion did not show this increase; its peak height was the same as that of the control reaction mixture $(\mathrm{PL}+\mathrm{Sd}$, No-R). Thus, $\mathrm{PL}$ in the chicken liver was satisfactory determined as shown in table 1. $\mathrm{PM}$ in the sample was determined by the reaction 2 in Fig. 2. Elution patterns of the two control reaction mixtures and reaction mixture spiked or non-spiked with PM are shown in Fig. 4B. Two controls (PM, No-R, and $\mathrm{PM}+\mathrm{Sd}$, No-R) showed the same peak height as those of (PL, No-R and PL $+\mathrm{Sd}$, No-R), respectively. In contrast, the peak height of the reaction mixture (PM, R) was higher than that of the reaction mixture $(\mathrm{PL}, \mathrm{R})$ because the former peak was a total of PL and PM. Thus, PM content was determined as shown in Table 1. Standard PM (2 pmol) was quantitatively converted into 4-PLA and determined $(\mathrm{PM}+\mathrm{Sd}, \mathrm{R})$. The $\mathrm{PN}$ in the chicken liver was determined by the reaction 3 in Fig. 2. Elution patterns are shown in Fig. 4C. Like PL and PM, PN was also quantitatively converted into 4-PLA and determined $(\mathrm{PN}+\mathrm{Sd}, \mathrm{R})$. The peak area of the reaction mixture $(\mathrm{PN}$, $\mathrm{R})$ was almost the same as that of the reaction mixture (PL, R), showing that the chicken liver sample contained a very low amount of PN. The PN content was determined as shown in Table 1.

Fig. 5A, B, and $\mathrm{C}$ shows the chromatograms for the analyses of PLP, PMP, and PNP. They showed similar but definitely different patterns of the fluorescent peaks of 4-PLA. The standard PLP, PMP, and PNP spiked could be accurately determined $(\mathrm{PLP}+\mathrm{Sd}, \mathrm{R} ; \mathrm{PMP}+\mathrm{Sd}, \mathrm{R}$; 
A
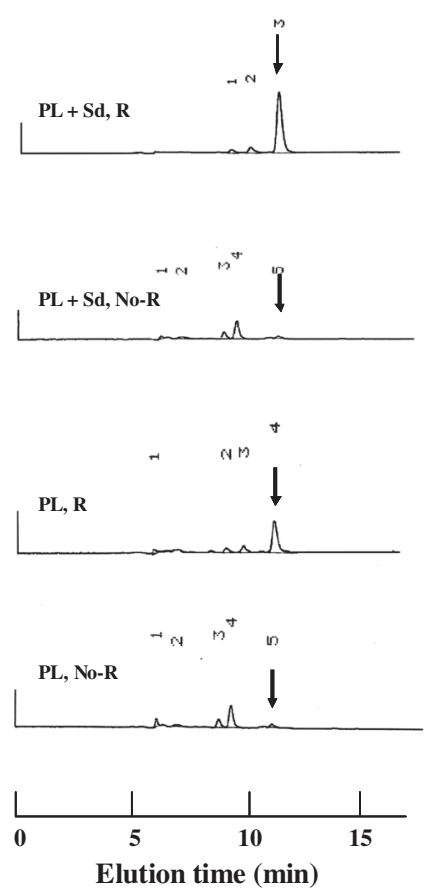

B
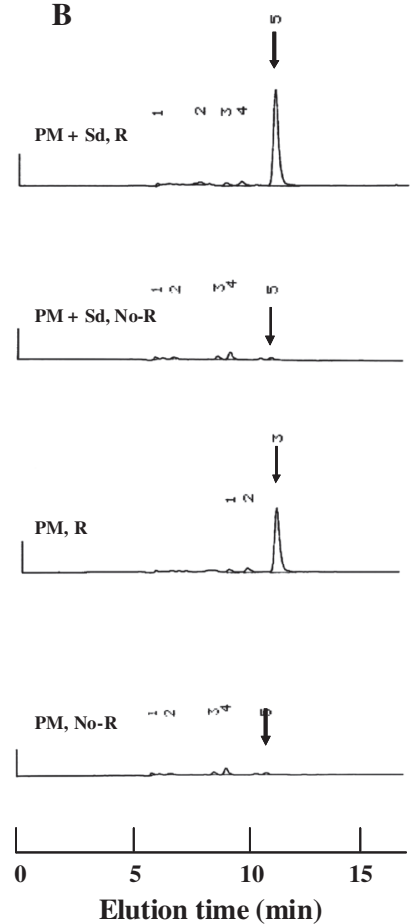
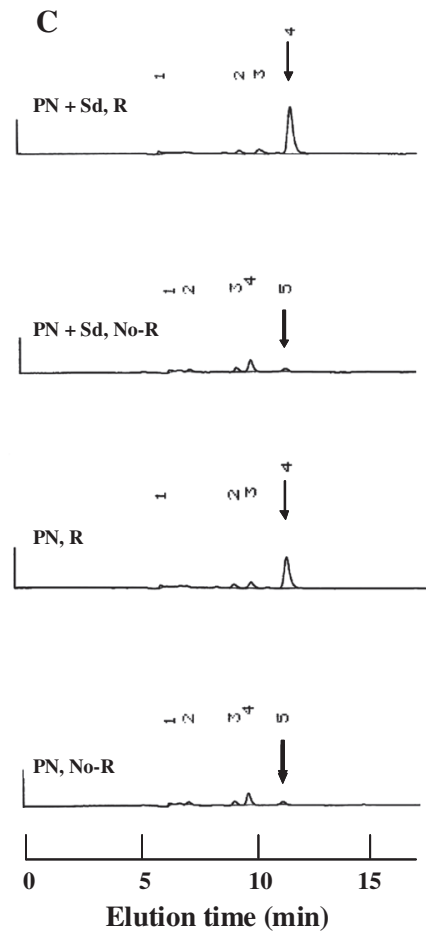

Fig. 4. HPLC chromatograms for the analyses of free forms of vitamin $\mathrm{B}_{6}$ in the chicken liver sample. The attenuation of the charts was $64 \mathrm{~mA} /$ full scale. Arrows show 4-PLA peaks. (A) PL was determined. The food sample (5 $\mu$ l) was subjected to the enzymatic conversion (the procedure for PL in Fig. 3) and applied to HPLC (PL, R). The food sample, to which standard $\mathrm{PL}$ had been added, was subjected to the enzymatic conversion (PL $+\mathrm{Sd}, \mathrm{R})$. Their controls were also done (PL, No-R, and PL $+\mathrm{Sd}$, No-R). (B) PM was similarly determined as shown in the procedure for PM in Fig. 3. (C) PN was similarly determined as shown in the procedure for PN in Fig. 3.

and $\mathrm{PNP}+\mathrm{Sd}, \mathrm{R})$. The peak area of PMP, $\mathrm{R}$ was high because it contained 4-PLA produced from PL, PM, PLP, and PMP. Thus, PMP content was calculated as shown in Table 1. Although the chromatograms obtained in the PNG analysis is not shown, PNG was also accurately determined.

The results showed that the method could be applied for the determination of contents of individual vitamin $\mathrm{B}_{6}$ compound in the chicken liver sample. No compound in the food samples interfered with the elution pattern of 4-PLA. The recovery of vitamin $\mathrm{B}_{6}$ compounds in the sample was between 73 and $92 \%$.

\section{Contents of vitamin $B_{6}$ compounds in the foods}

The contents of seven vitamin $B_{6}$ compounds in the foods were successfully determined (Table 2 ). The values are in $\mathrm{nmol} / \mathrm{g}$, except for the total content that also is calculated as $\mathrm{PN}, \mathrm{HCl}$. Although the recovery varied a lot among foods, the recovery tests could be determined for all the foods, showing that the present method for preparation of the food samples was almost adequate for the presented method: the standard deviation of the recovery for chicken liver, egg yolk and white, and dried small anchovy are shown in (Table 2). The recovery of PLP in the egg yolk and the dried anchovy was only 14 and $29 \%$, respectively. These results indicate that PLP in these foods bind so strongly to the other food component(s) that ALP cannot hydrolyze PLP bound to them. Thus, improvement of the sample preparation method is required, although it is better than $\mathrm{HCl}$-hydrolysis (9), in which recoveries of PLP and PM in garlic could not be estimated. The difficulty of PLP recovery from tissue samples has been described (18). Another explanation could be that the egg yolk and dried anchovy contain some compounds that inhibit ALP. Although it is not clear what happens, the bioavailability of PLP in the egg yolk and anchovy may be low, because it is well known that ALP activity correlates significantly with in vivo luminal disappearance of PLP (19). This method may not be applicable for the foods that give a too low recovery of the vitamin $\mathrm{B}_{6}$ compounds. In such cases, it is necessary to develop an improved preparation method for the food samples. The evaluation of applicability of the method based on the recovery is required.

Total contents (as $\mathrm{PN}-\mathrm{HCl}$ ) of vitamin $\mathrm{B}_{6}$ compounds and PNG, which have been determined by a microbiological method, are described in the Japanese Food Table. They are $35.5 \mathrm{nmol} / \mathrm{g}$ for chicken white meat; 38.4, chicken liver; 15.4, egg yolk; 0, egg white; 6.5, carrot; 6.5 , garlic; and 16.6, dried small anchovy. The values in 

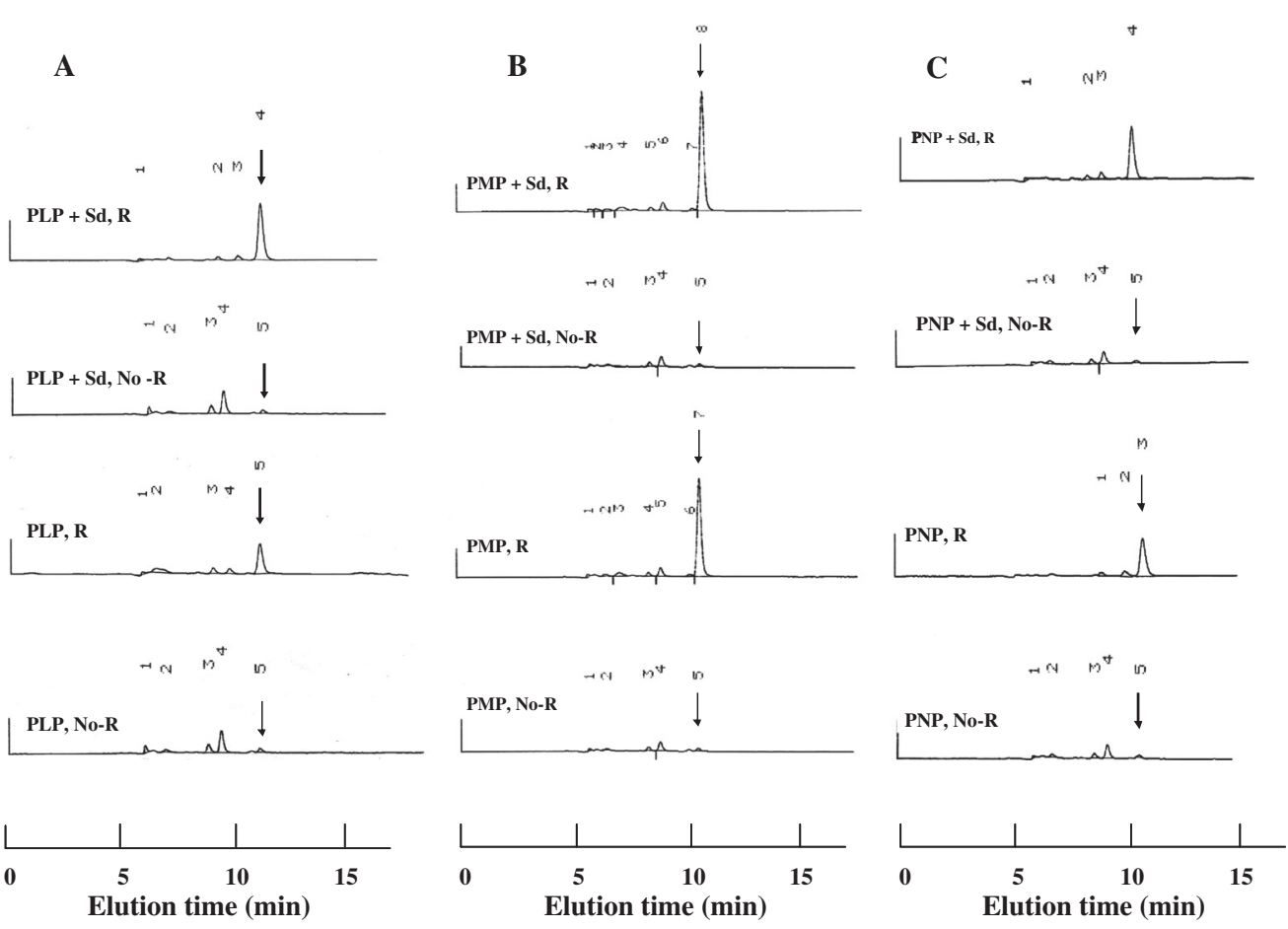

Fig. 5. HPLC chromatograms for the analyses of phosphoester forms of vitamin $\mathrm{B}_{6}$ in the chicken liver sample. The attenuation of the charts was $64 \mathrm{~mA} /$ full scale. Arrows show 4-PLA peaks. (A) PLP was determined. The food sample (5 $\mu$ l) was subjected to the enzymatic conversion (the procedure for PLP in Fig. 3) and applied to HPLC (PL, R). The food sample, to which standard PLP had been added, was subjected to the enzymatic conversion (PLP $+\mathrm{Sd}, \mathrm{R})$. Their controls were also done (PLP, No-R, and PLP + Sd, No-R). (B) PMP was similarly determined as shown in the procedure for PMP in Fig. 3. (C) PNP was similarly determined as shown in the procedure for PNP in Fig. 3.

$\mathrm{nmol} / \mathrm{g}$ were converted from values given as $\mathrm{mg} / 100 \mathrm{~g}$ of an edible part in the Japanese Food Table. The microbiological and the present methods gave similar values for the contents in the chicken white meat and liver. In contrast, higher values were obtained for the other samples with the present method; in particular, the small dried anchovy had about 9-fold higher value. Because its content is in $\mathrm{nmol} / \mathrm{g}$, dry weight, in contrast to the other samples, the value obtained by the present method seems to be rational, suggesting that vitamin $\mathrm{B}_{6}$ compounds in the dried small anchovy could not be measured accurately by the microbiological method. The preferred comparison would be to measure the same food samples by the microbiological method and the present method.

PNG was found only in the plant-derived foods. The results coincided well with the previous report (20). The relative contents of PNG were 19 and $42 \%$ of the total content in garlic and carrot, respectively. The PNG contents in plant-derived food have been reported to vary from $0 \%$ (cauliflower) (3) to $92 \%$ (orange juice) (20). The contents of $\mathrm{PN}$, which is generally used as a supplement of vitamin $\mathrm{B}_{6}$ for fortified foods, were very low in the foods examined; actually PN was not found in either chicken white meat or egg yolk. Although analytical data for many other foods are required, the results suggest a need for studies to determine which of the vitamin $\mathrm{B}_{6}$ compounds should be used for fortification of the food.

Each of the foods analyzed showed a characteristic pattern of the seven vitamin $\mathrm{B}_{6}$ compounds. Both $\mathrm{PM}$ and PMP were high in the chicken liver. In contrast, PL and PLP were high in the chicken white meat. The main vitamin $B_{6}$ in the egg yolk was PLP. The dried anchovy contained high amounts of PLP, PMP, and PNP; the free forms were very low. Both the PLP and PL were high in the garlic.

Traditionally, the dried small anchovy has been used for making stock soup in Japan. However, recently, a new preparation for taking the whole body as a food has been developed, which is the sample used in this study. Because PMP should be absorbed as PM in the intestine after the hydrolysis by the ALP, which shows reactivity toward PMP as well as PLP, PMP should have the same efficacy as PM in the anti-diabetic complications. Thus, the chicken liver and the dried small anchovy may be candidates for foods functioning to prevent diabetic complications.

The present method needs seven enzymatic reactions plus HPLC analysis. The time needed for determination of seven vitamin $\mathrm{B}_{6}$ compounds in one food by a trained student was approximately 10 days. Although the first analysis was finished within 2 days, the additional days 
Table 2. Contents of vitamin $\mathrm{B}_{6}$ compounds and PNG in chicken liver and white meat, egg yolk and white, dried small anchovy, carrot, and garlic; recoveries of the standards are also shown

\begin{tabular}{|c|c|c|c|c|c|c|c|}
\hline & Chicken liver & Chicken white meat & Egg yolk & Egg white & Dried small anchovy & Carrot & Garlic \\
\hline $\mathrm{PL}(\mathrm{nmol} / \mathrm{g})$ & $7.4 \pm 0.2$ & $21.1 \pm 0.4$ & $6.2 \pm 0.3$ & ND & $1.7 \pm 0.8$ & $1.2 \pm 0.0$ & $6.4 \pm 0.5$ \\
\hline Recovery (\%) & $73 \pm 2.0$ & 96 & $4 I \pm 3.3$ & $64 \pm 3.7$ & $75 \pm 0.1$ & 63 & 106 \\
\hline $\mathrm{PM}(\mathrm{nmol} / \mathrm{g})$ & $17.9 \pm 0.6$ & $2.0 \pm 0.1$ & $2.3 \pm 0.1$ & ND & $2.2 \pm 0.2$ & $1.3 \pm 0.0$ & $0.8 \pm 0.1$ \\
\hline Recovery (\%) & $86 \pm 1.4$ & 68 & $54 \pm 3.5$ & $50 \pm 0.7$ & $97 \pm 0.5$ & 58 & 92 \\
\hline $\mathrm{PN}(\mathrm{nmol} / \mathrm{g})$ & $0.4 \pm 0.0$ & ND & ND & $1.8 \pm 0.1$ & $3.4 \pm 0.4$ & $0.6 \pm 0.0$ & $3.5 \pm 0.3$ \\
\hline Recovery (\%) & $87 \pm 1.0$ & 91 & $85 \pm 4.6$ & $53 \pm 2.3$ & $93 \pm 0.2$ & 103 & 85 \\
\hline PLP (nmol/g) & $1.2 \pm 0.0$ & $13.5 \pm 0.2$ & $34.0 \pm 1.6$ & $1.2 \pm 0.0$ & $113.7 \pm 5.9$ & $2.2 \pm 0.2$ & $7.1 \pm 0.2$ \\
\hline Recovery (\%) & $92 \pm 7.1$ & 80 & $14 \pm 1.9$ & $41 \pm 1.9$ & $88 \pm 0.1$ & 32 & 102 \\
\hline PMP (nmol/g) & $8.4 \pm 0.1$ & $4.8 \pm 0.2$ & $1.0 \pm 0.0$ & ND & $22.9 \pm 2.3$ & $2.6 \pm 0.1$ & $4.2 \pm 1.2$ \\
\hline Recovery (\%) & $87 \pm 0.4$ & 109 & $52 \pm 4.7$ & $73 \pm 2.5$ & $77 \pm 0.4$ & 54 & 96 \\
\hline PNP (nmol/g) & $6.8 \pm 0.1$ & $1.3 \pm 0.0$ & $7.5 \pm 0.2$ & ND & ND & $2.1 \pm 0.1$ & $1.0 \pm 0.0$ \\
\hline Recovery (\%) & $80 \pm 0.1$ & 91 & $62 \pm 3.4$ & $97 \pm 1.9$ & $62 \pm 2.8$ & 51 & 83 \\
\hline PNG (nmol/g) & ND & ND & ND & ND & ND & $7.3 \pm 0.2$ & $5.4 \pm 0.0$ \\
\hline Recovery (\%) & $92 \pm 4.0$ & 95 & $102 \pm 0.3$ & $118 \pm 4.3$ & $90 \pm 1.0$ & 58 & 74 \\
\hline Total $(\mathrm{nmol} / \mathrm{g})$ & $42.2 \pm 0.2$ & $42.7 \pm 2.3$ & $50.9 \pm 0.4$ & $3.0 \pm 0.1$ & $143.9 \pm 6.6$ & $17.3 \pm 0.2$ & $28.4 \pm 2.4$ \\
\hline$(\mu \mathrm{g} / / 00 \mathrm{~g})^{*}$ & $868.0 \pm 4.2$ & $878.3 \pm 31.3$ & $1,047.0 \pm 12.9$ & $61.7 \pm 2.2$ & $2,959.9 \pm 18.2$ & $355.8 \pm 2.3$ & $584.1 \pm 43.0$ \\
\hline
\end{tabular}

ND means $=$ not detectable.

The average $\pm S D$ of three experiments are shown.

*Molecular weight of $\mathrm{PN}-\mathrm{HCl}$ is 205.69 .

were required to determine recoveries of the recovery test. The present method is not a method for routine work under the present conditions. Thus, the development of a determination kit consisting of the seven reaction mixtures and the seven standard compounds would be necessary to facilitate easier routine analysis of the food samples. We are continuing our investigations to develop the kit.

\section{Conclusions}

The present method was applicable for determination of all seven vitamin $\mathrm{B}_{6}$ compounds. The method was applied on samples derived from animal, vegetables, and fish. Their distribution in the foods varied significantly. The content of PN that is used for fortification of foods was very low in the foods examined. The present method needs improvement in the speed of the analysis.

\section{Conflict of interest and funding}

This work was partially supported by the Ministry of Education, Culture, Sports, Science and technonogyJapan, Grant-in-Ais for Exploratory Research, 18650215, 2007, and by a Kochi University President's Discretionary Grant.

\section{References}

1. Gregory JF III. Relative activity of the nonphosphorylated B-6 vitamers for Saccharomyces uvarum and Kloeckera brevis in vitamin B-6 microbiological assay. J Nutr 1982; 112: 1643-7.

2. Tsuge H, Nishimura N, Maeno M, Hayakawa T. Investigation on acid hydrolysis conditions for the determination of total vitamin $\mathrm{B}_{6}$ contents in food [in Japanese]. Vitamins (Japan) 1995; 69: 689-96.

3. Kall MA. Determination of total vitamin $B_{6}$ in foods by isocratic HPLC: a comparison with microbial analysis. Food Chem 2003; 82: 315-27.

4. Mahon LG, Nakano H, Levy M-D, Gregory JF III. Cytosolic pyridoxine- $\beta$-D-glucoside hydrolase from porcine jejunal mucosa. J Biol Chem 1997; 272: 32025-33.

5. Williams ME. New potential agents in treating diabetic kidney disease: the fourth act. Drugs 2006; 66: 2287-98.

6. Chumnantana R, Yokochi N, Yagi T. Vitamin $\mathrm{B}_{6}$ compounds prevent the death of yeast cells due to menadione, a reactive oxygen generator. Biochim Biophys Acta 2005; 1722: 84-91.

7. Mahuren JD, Coburn SP. Determination of 5-pyridoxic acid, 5-pyridoxic acid lactone, and other vitamin $\mathrm{B}_{6}$ compounds by cation-exchange high-performance liquid chromatography. Methods Enzymol 1997; 280: 22-9.

8. Edwards P, Liu PK, Rose GA. A simple liquid-chromatographic method for measuring vitamin $\mathrm{B}_{6}$ compounds in plasma. Clin Chem 1989; 35: 241-5.

9. Nishimura S, Nagano S, Chan AC, Yokochi N, Yoshikane Y, $\mathrm{Ge} F$, et al. Determination of individual vitamin $\mathrm{B}_{6}$ compounds based on enzymatic conversion to 4-pyridoxolactone. J Nutr Sci Vitaminol 2008; 54: 18-24. 
10. Yokochi N, Nishimura S, Yoshikane Y, Ohnishi K, Yagi T. Identification of a new tetrameric pyridoxal 4-dehydrogenase as the second enzyme in the degradation pathway for pyridoxine in a nitrogen-fixing symbiotic bacterium, Mesorhizobium loti. Arch Biochem Biophys 2006; 452: 1-8.

11. Yoshikane Y, Yokochi N, Ohnishi K, Hayashi H, Yagi T. Molecular cloning, expression and characterization of pyridoxamine-pyruvate aminotransferase. Biochem J 2006; 396: 499-507.

12. Yuan B, Yoshikane Y, Yokochi N, Ohnishi K, Yagi T. The nitrogen-fixing symbiotic bacterium Mesorhizobium loti has and expresses the gene encoding pyridoxine 4-oxidase involved in the degradation of vitamin $\mathrm{B}_{6}$. FEMS Microbiol Lett 2004; 234: 225-30.

13. Sambrook J, Fritsch EF, Maniatis T. Molecular cloning: a laboratory manual. 2nd ed., 3 vols. New York: Cold Spring Harbor Laboratory Press; 1989.

14. Stock A, Ortanderl F, Pfleiderer G. Darstellung von radioakiv markiertem pyridoxal 5'-phosphat. Biochem Z 1966; 344: $353-60$.

15. Wada K, Asano Y. Use of borate to control the 5'-positionselective microbial glucosylation of pyridoxine. Biosci Biotech Biochem 2003; 69: 7058-62.

16. $\mathrm{Xu} \mathrm{X}$, Kantrowitz ER. Binding of magnesium in a mutant Escherichia coli alkaline phosphatase changes the rate-determining step in the reaction mechanism. Biochemistry 1993; 32: 10683-91.
17. Bauer MW, Bylina EJ, Swanson RV, Kelly RM. Comparison of a $\beta$-glucosidase and a $\beta$-mannosidase from the hyperthermophilic archaeon Pyrococcus furiosus. Purification, characterization, gene cloning, and sequence analysis. J Biol Chem 1996; 271: 23749-55.

18. Snell EE. Vitamin $B_{6}$ analysis: some historical aspects. In: Leklem JE, Reynolds RD, eds. Methods in Vitamin B-6 nutrition. New York: Plenum Press; 1980, pp. 1-20.

19. Middleton HM III. Pyridoxal 5'-phosphate disappearance from perfused rat jejunial segment: correlation with perfusate alkaline phosphatase and water absorption. Proc Soc Exp Biol Med 1983; 174: 249-57.

20. Gregory JF III, Ink SL. Identification and quantification of pyridoxine- $\beta$-glucoside as a major form of vitamin $B_{6}$ in plantderived foods. J Agric Food Chem 1987; 35: 76-82.

\section{*Toshiharu Yagi}

Faculty of Agriculture and Agricultural Science Program

Graduate School of Integrated Arts and Sciences

Kochi University

Monobe-Otsu 200

Nankoku, Kochi 783-8502, Japan

Fax: +81888645191

Email: yagito@kochi-u.ac.jp 